\title{
Humanitarian access, interrupted: dynamic near real-time network analytics and mapping for reaching communities in disaster-affected countries
}

\author{
Martijn Warnier ${ }^{1} \cdot$ Vincent Alkema $^{1} \cdot$ Tina Comes $^{1} \cdot$ Bartel Van de Walle $^{1}$
}

Received: 29 March 2019 / Accepted: 19 February 2020 / Published online: 4 March 2020

(c) The Author(s) 2020

\begin{abstract}
In the immediate aftermath of a disaster, local and international aid organisations deploy to deliver life-saving aid to the affected population. Yet pre-disaster road maps and road transportation models do not capture disruptions to the transportation network caused by the disaster or the dynamic changes of the situation, resulting in uncertainty and inefficiency in planning and decision-making. The integration of data in near real time on the status of the road infrastructure in the affected region can help aid organisations to keep track of the rapidly shifting conditions on the ground and to assess the implications for their logistics planning and operations. In this paper, we present a rapid graph-theoretical reachability information system based on a combination of OpenStreetMap and open humanitarian data. The system supports logistics planning in determining road access to affected communities. We demonstrate the results of our approach in a case study on the 2018 earthquake in Papua New Guinea. Our findings show the reachability of affected communities depending on the actual status of the road network, allowing for the prioritization of targeted locations and the identification of alternative routes to get there.
\end{abstract}

Keywords Reachability - Access · Network analysis · Humanitarian logistics · Sudden-onset disaster response

Martijn Warnier

M.E.Warnier@tudelft.nl

Tina Comes

T.Comes@tudelft.nl

Bartel Van de Walle

B.A.vandeWalle@tudelft.nl

1 Faculty of Technology, Policy and Management, Delft University of Technology, Delft, The Netherlands 


\section{Introduction}

In the response to a humanitarian disaster, the international humanitarian community mobilises to cater for the most urgent humanitarian needs, such as provision of shelter, food, water and sanitation and healthcare. Humanitarian logistics is about gaining access and 'mobilising people, resources, skills and knowledge to help vulnerable people affected by disaster' (Van Wassenhove 2006). In the early phase of a natural disaster, response organisations rush towards the still functioning seaports and airports that serve as entry points to reach the affected areas (Holguín-Veras et al. 2012). Yet destruction of road infrastructure can lead to severe delays, particularly for rural communities, such as during the Nepal earthquake of 2015, where mountain trails became impassable, and communities could only be reached by Sherpa (Kazmin 2015; Baharmand et al. 2017).

Information is widely viewed as one of the determinants for the success of a humanitarian logistics supply chain (Van de Walle and Comes 2015; Huyck et al. 2014; Comes et al. 2015). The 2010 Haiti Earthquake marked the beginning of a new paradigm 'Disaster Response 2.0' (Harvard Humanitarian Initiative (HHI) 2010), promoting a data-driven response relying increasingly on social media and crowdsourced information (Altay and Labonte 2014; Comes et al. 2017). Since then, there is an increasing amount of literature that reflects on the possibilities of data analytics in disaster response (Palen and Anderson 2016; Meier 2015; Comes et al. 2018; Papadopoulos et al. 2017).

Much research in humanitarian operations management focuses on developing or improving optimisation models (Özdamar and Ertem 2015). However, this research is often disconnected from the potential of predictive analytics or rapid analysis that allows responders to understand in near real time what the status of the transportation network is and how vulnerable communities can be reached. This paper aims to address the lack of dynamic information updates about road networks and access to local communities in disaster response. Thereby, we contribute to improving situational awareness of humanitarian responders, and providing rapid input that can facilitate parametrisation and updates of traditional optimisation models.

We focus here on situations that are highly dynamic and uncertain. Based on approaches from complex network analysis (Ben-Naim et al. 2004), this paper develops an information system that uses available (open) data to analyse reachability of affected communities via road networks. Through a dynamic representation, humanitarian responders can receive rapid updates about hard to reach areas and critical locations or connections, thereby improving their situational awareness.

The remainder of the paper is structured as follows: we first provide background on situational awareness, crisis mapping, and network analysis. Subsequently, we present our methodology and research design in Sect. 3. The design of the reachability information system is presented in Sect. 4. To illustrate and validate our approach, we apply our information system to the 2018 Earthquake in Papua New Guinea (Sect. 5). We conclude with a discussion and implications for research and practice. 


\section{Background}

Rapidly reaching people in need of assistance is key to effective disaster response. Entry points such as seaports and airports serve as hubs to offload goods, break bulks, package or assemble different goods to kits (Laguna-Salvadó et al. 2018). To reach the people in need, the goods are further distributed. Recently, there is increasing attention for the use of humanitarian drones to distribute goods independently from (road) infrastructure, particularly in medical applications (Comes et al. 2018; Chowdhury et al. 2017; Tatham et al. 2017b). However, there are important restrictions that limit the use of drones particularly in large-scale disasters, ranging from the volume and weight of required transportation, to regulatory issues, weather conditions and ethical considerations (van Wynsberghe and Comes 2019). Therefore, road transportation remains the dominant mode of transportation, in particular to ship bulk goods, and the main mode considered in the humanitarian (last mile) distribution literature (Balcik et al. 2008; Anaya-Arenas et al. 2014).

At the same time, most disasters cause population movements, as people try to escape dangerous zones or destroyed livelihoods (Lu et al. 2012). The road network is hence key to relief distribution and the mobility of local population and goods (Jenelius and Mattsson 2012). As such, one of the most important aspects for humanitarian responders is to understand the status of the road network, its vulnerabilities and the main uncertainties related to its status. This information can, in turn, inform most other decisions that logisticians will need to make, ranging from facility location, to distribution planning, routing or scheduling decisions.

In the following, we provide background on three key areas for our work: (1) the need for improved sensemaking in dynamic and highly uncertain situations; (2) an overview of the data landscape in crisis mapping; and (3) network analysis for humanitarian logistics.

\subsection{The need for improved situational awareness}

Despite the global penetration of information technology, the ubiquity of social media and 'Big Data', information on a disaster's impact is still typically incomplete, biased, uncertain, conflicting and highly volatile (Van de Walle and Comes 2015; Balcik et al. 2010). The standard paradigm suggests that as time passes more information will become available and reduce uncertainty to allow for better informed and justified decisions. Yet, disasters usually will not steadily transition from a chaotic situation into a stable state where optimal decisions can be made. Instead, decision-makers face a situation where problems and the information required to solve them evolve dynamically and create nested and interdependent decision sequences (Comes et al. 2011). Therefore, there is a need for continuous rapid updates that provide responders with situational awareness on the most critical elements of a humanitarian operation.

Commonly, one distinguishes situational awareness data from programmatic data such as background information on demographics or culture (Prasad et al. 2018). We here focus on the first category, which covers information about the latest conditions, 
needs, and locations of vulnerable populations. As such, situational awareness data are also the most dynamic, uncertain and volatile.

Generally, situational awareness is defined as 'the perception of the elements in the environment within a volume of time and space, comprehension of their meaning and the projection of their status in the near future' (Endsley 1988, p. 97). Situational awareness during the disaster response phase is important for effective disaster management, as the available information will guide aid workers in their relief operations (Van de Walle et al. 2016). Crucially, situational awareness is related to the available interpretable information about elements in a disaster-struck area and how this information changes over time.

Despite the many sources such as news reports, maps and situation reports, situational awareness remains a problem in humanitarian response (Tomaszewski 2011). While there is a need for data from the ground, reports often are inaccurate, conflicting with other reports and incomplete in terms of geographical or temporal details (Madey et al. 2007). This is particularly true for social media-generated content (Palen and Anderson 2016). Therefore, it is important to have a structured representation of available data that allows to understand and prioritize critical information.

Several authors argued that there is a need for improved information systems to navigate the uncertainty and dynamics characteristic for humanitarian response (Chandes and Paché 2010; Salvadó et al. 2015; Tatham et al. 2017). While there is as such consensus that information systems and data analyses can contribute to response organisations, the literature largely focuses on deriving design principles (Bharosa et al. 2010; Comes and Van de Walle 2016; Turoff et al. 2004; Van de Walle et al. 2008). What is currently missing, is a clear operational overview, in particular for transportation and (last mile) distribution (Tatham et al. 2017). To start bridging this gap, we focus here on the aspect of access and propose a design of an information system that helps to reduce the risk of people becoming isolated. As such, we aim to make a headway in the broader discussion on how to develop, design and use predictive analytics in the early phase of a response.

\subsection{Leveraging crisis mapping}

Maps and geographic information systems remain the most commonly used information products and tools in the response to crises. Indeed, obtaining geographic situational awareness has been described as a critical success factor in sudden-onset disaster response (Harrald 2006; Tomaszewski 2011) as they are a means of providing reports including geographical and temporal details.

Geographic visualisation techniques have been developing rapidly over the previous decades and continue to drive vulnerability mapping applications (Preston et al. 2011), or mapping of crisis related information from social media (Huang and Xiao 2015; Middleton et al. 2014). OpenStreetMap is the most widely used volunteer geographic information system, and the maps that are essentially built by digital volunteers are by now considered as the most up-to-date, accurate, or accessible map of affected areas by many humanitarians (Kogan et al. 2016). The power of OpenStreetMap is in the emphasis of local knowledge, which can be a great advantage in areas where 
governmental road network administration is not properly maintained. Also, in natural disasters, the state of a road network may change drastically, where OpenStreetMap allows changes to be made by local observers that have first-hand information about the developments. Furthermore, its data are available to anyone for free.

We aim to leverage the potential of these maps to create geographic reachability maps, giving a clear insight into the access conditions and key vulnerabilities of the road and transportation network as a disaster unfolds. As such, this approach complements more traditional vulnerability mapping in disaster risk reduction (Birkmann 2007) with dynamic information and rapid updates on the reachability of communities as a factor that drives disaster vulnerability.

\subsection{Network analysis for humanitarian logistics}

Network analysis, which has its roots in graph theory, is one of the most prominent approaches to characterise distribution networks (Easley and Kleinberg 2010), as it provides a method for analysing how the topological structure and connectedness of a network influences its performance (Bell and Iida 1997). Centrality measures can be used to identify the importance of a particular part of the network such as a specific road or town (Easley and Kleinberg 2010; Hernandez and Van Mieghem 2011).

Graph theoretic analysis of transportation networks is common in the literature, and there are some papers that use these techniques for disaster logistics and resilience. For example, Guimerá and Amaral (2004) discuss how critical airports in disaster areas can be identified using degree centrality and betweenness centrality. Their study focuses on inter-airport connectivity, but does not discuss the relation of airports with the road network. Schintler et al. (2007) and Mitsakis et al. (2016) study the resilience of transportation networks and the impact of disruptions on specific segments. Albert et al. (2000) use a topological connectivity metric to analyse error tolerance in a variety of systems. Aydin et al. (2018) use graph-based topological metrics to stress test the resilience of urban road networks. All these publications focus on longer-term planning, either in a pre-disaster context or for recovery. What is missing is a rapid approach that focuses on capturing the dynamics of a disaster.

Purely topological approaches assume that aid workers follow the shortest path between two nodes, where the most efficient path is typically the shortest or the fastest path, determined by considering road length and maximum allowed driving speed. These approaches fail to capture more dynamic information, such as road accessibility, quality or congestion. Such dynamic properties, however, can determine the importance of elements in the network (Strogatz 2001; Boccaletti et al. 2006; Cats et al. 2017). Our approach therefore extends the purely topological metrics in transportation networks by integrating dynamic properties of the transportation network.

\section{Methodology}

To analyse the reachability of communities, we follow a design science approach (Hevner et al. 2004), combining literature on humanitarian logistics and situational 
awareness with graph-theoretical models and visualisations. This approach results in a reachability model that provides an overview on road travel times, providing an indication on access conditions to humanitarian organisations. To illustrate and validate our approach, we use a case study on Papua New Guinea in Sect. 5. Finally, we discuss our findings and draw conclusions.

\subsection{Case study design, data requirements and collection}

The case study on Papua New Guinea is chosen for the importance of logistics and access conditions, and adequate scale allowing for a full exploration of the modelled road network.

Our model and approach require data on the logistics network in terms of the entry points (airports, seaports), their capacity, and their connection to the road network. This is typically information that is available a priori from data sources such as OpenStreetMap, which we use here.

To determine reachability after a disaster, we integrate dynamic information reflecting humanitarian needs, infrastructure quality and travel times, all of which are typically available from the Logistics Cluster $^{1}$ and situation reports accessible via reliefweb. ${ }^{2}$ Furthermore, risk levels need to be determined, both in terms of possible aftershocks and access restrictions. This data needs to be integrated with geographic information (such as coordinates), a geographic map of the region and shape-files of areas where communities live in the region such as increasingly available via the Humanitarian Data Exchange Portal HDX. ${ }^{3}$

As such, our approach connects to the current humanitarian data landscape. At the same time, it is possible for humanitarian organisations to integrate their own assessments and updates based on information they receive from the field.

For the case study of Papua New Guinea, data collection relied on OpenStreetMap data for the topography and general road network, combined with information from the Logistics Cluster and situation reports from UN agencies accessible via reliefweb. int, such as access conditions (World Food Program 2018), population data (United Nations Papua New Guinea 2018) and damage assessments (European Union 2018).

\subsection{Choice of metrics}

There is a wide variety of metrics available in transportation network analysis (see Sect. 2.3). This section provides our motivation for the specific choices of graph theoretical measures and algorithms, combining topological measures and intrinsic

\footnotetext{
1 The logistics cluster provides logistics-related operational updates; information about road infrastructures and access; meeting minutes and standard operating procedures for a wide range of countries and disasters on https://logcluster.org/.

2 Reliefweb is a digital platform provided by the UN Office for the Coordination of Humanitarian Affairs (OCHA) to streamline humanitarian information sharing https://reliefweb.int/.

3 HDX is the data-portal of OCHA, providing a rich set of geographical, demographic and disaster-related information on https://data.humdata.org/.
} 
information of the network elements. All metrics provide essential information that easily can be visualised in a map.

Centrality measures We have chose node betweenness and edge betweenness centrality, which have been advocated to determine the disaster resilience of transportation networks (Aydin et al. 2018). The node betweenness centrality indicates the number of shortest paths between any pair of nodes crosses a certain node and the edge betweenness centrality indicates the number of shortest paths between any pair of nodes crosses a certain edge, see Sect. 4 for more details. This centrality measure how centrally located a certain node or edge is in the network. The betweenness centrality is calculated for each node and edge and then added as an attribute for each node and edge. The ten most critical nodes, i.e., those nodes with the highest betweenness centrality, are visualized and indicated by larger black dots on the generated map. These indicate road crossings that are of high importance for the internal connectivity and thus reachability in the network.

Intrinsic network properties represent the 'static' features of the network that are not affected by the disaster (Comes and Van de Walle 2016; Prasad et al. 2018), in our case, we refer to the roads in the network. We include the length of a road segment, the number of lanes on a road segment, the time it takes to cross a road segment completely and the maximum allowed speed that can be driven on a road segment. We use maximum allowed speed as an approximation for the road traversal speed that is safe to use for rescue operators. All features are captured as attributes of the edges within the model and can be visualized in the generated maps.

Dynamic network properties represent the 'dynamic' and volatile situational updates in the context of a disaster (Comes and Van de Walle 2016; Prasad et al. 2018), or in this case, the network properties that can change, such as road quality or congestion (traffic jams). Here, we focus on the quality of road segments, leaving congestion for future work. Initially, the road quality for all road segments will be considered as good, meaning accessible, but as more information becomes available this can be changed for each road. Where a lower road quality affects the travelling speed for a road segment.

By themselves the above metrics do not provide much insight, but when combined, interpreted in context and used to generate a visual representation they can contribute to an accurate situational awareness with respect to the reachability of communities during sudden onset disasters. The next section explains this process in more detail.

\section{Modelling reachability with network analysis}

This section gives an high-level overview of the construction of the reachability model. The model realised is in the form of an information system implemented in Python using (amongst others) the OSMnx, networkX and geopandas libraries. The full code is available in the form of a Jupyter notebook at github under an open source licence. ${ }^{4}$ The modelling process is divided into three main phases: (1) Creating the graph network; (2) Determining network attributes; (3) Determining reachability and visualisation.

\footnotetext{
4 See https://github.com/vipalkema/MSc-Thesis-MakingReachabilityMaps.
} 


\subsection{Phase 1: creating the graph network}

In the first phase in the modelling process, all required road network data are imported from OpenStreetMap. A query is constructed for a specific location based on user provided input. This query results in geometry data for the specified region, which is subsequently converted into a multi-directional graph network. All nodes and edges in the resulting graph have several attributes providing information such as the identifier of a node or edge, the length of an edge or the name of a street that is represented by an edge. Entry point nodes such as airports or seaports are labelled.

\subsection{Phase 2: determining graph network attributes}

In the second phase, several graph attributes are determined: the travel time for each edge, the flow time of each edge, the betweenness centrality of the edges and the nodes, and the betweenness centrality for the entry points.

To determine the travel time for each edge, the information that is stored in the multi-directional graph generated in the previous phase is used. Travel times for each edge are determined based on the road length, speed limit information, average speed information (provided by the user) and road quality information. Equation (1) is used to determine the travel time for an edge:

$$
t=\frac{l}{v_{\text {meters } / \text { minute }} * \frac{1}{1+\mathrm{e}^{-10 Q-0.5}}}
$$

here $t$ is the travel time in minutes, $v_{\text {meters/minute }}$ is the speed in meters per minute from either the maximum allowed speed or the average speed and $Q$ is the road quality on a scale from 0 to 1 , where 0 is the lowest possible road quality meaning that the road is completely inaccessible, while 1 corresponds to the pre-disaster state. Travel times per edge are determined by average travel times (if available, e.g., from the logistics cluster), or by using OpenStreetMap standard travel times. The length is divided by the speed multiplied by the impact factor of the road quality and the road quality itself. The impact of the road quality on the speed follows a sigmoid function (also known as an $S$-curve). The sigmoid function is used to model the impact of the road quality. Road quality information can be updated manually, when new information becomes available. The 'flow time' which takes road capacity (type of road; number of lanes) into account is also determined in this phase. This allows us to prioritize the main roads that are vital to set up a distribution network.

The flow time represents the combination of the time it takes to cross an edge together with the amount of parallel lanes the road has. Formally, the metric is determined by dividing the time it takes to cross an edge by the number of lanes. The flow time thus models the flow of goods per time unit on a road. Flow time can be used as a routing option in the reachability model. Making roads with higher capacity more attractive to choose when looking for the shortest path compared to roads with lower capacity. 
In addition, the edge-betweenness centrality and the entry point subset edgebetweenness for all shortest paths through the entry points in the network are determined. The subset edge-betweenness centrality gives insight into the criticality of the roads in terms of reachability of each of the entry points by other nodes. The higher the subset edge-betweenness centrality, the more critical the road is for travelling between any node and the most reachable entry points (Brandes 2001). Formally the subset edge-betweenness centrality $\left(c_{\mathrm{B}}(e)\right)$ is determined by Eq. (2)

$$
c_{\mathrm{B}}(e)=\sum_{s \in S, t \in T} \frac{\sigma(s, t \mid e)}{\sigma(s, t)}
$$

where $S$ is the set of sources, $T$ is the set of targets, $\sigma(s, t)$ is the number of shortest $(s, t)$-paths, and $\sigma(s, t \mid e)$ is the number of those paths passing through edge $e$ (Brandes 2001). The set of sources $(S)$ are the entry point nodes identified earlier, the targets $(T)$ are all other nodes in the graph network.

The entry point nodes are part of the network and their importance also needs to be determined. The betweenness centrality of the entry points indicates how well-located the entry point is within the network. The higher the betweenness centrality, the better the entry point is located to be reached by any node in the network. Equation (3) is used to determine the entry point betweenness centrality.

$$
c_{\mathrm{B}}(v)=\sum_{s, t \in V} \frac{\sigma(s, t \mid v)}{\sigma(s, t)}
$$

where $V$ is the set of nodes, $\sigma(s, t)$ is the number of shortest $(s, t)$-paths, and $\sigma(s, t \mid v)$ is the number of those paths passing through some node $v$ other than $s, t$. If $s=t$, $\sigma(s, t)=1$, and if $v \in s, t, \sigma(s, t \mid v)=0$ (Brandes 2008).

\subsection{Phase 3: determine the reachability and visualisation}

In this phase, the reachability is determined by calculating the travel time from the entry points to all other nodes in the network. Dijkstra's shortest-path algorithm (Dijkstra 1959) is used to calculate the shortest distance between any node pair in the graph. The user can specify if travel time, edge length, or flow time are used for this. It is also possible to generate the three models concurrently, making it easier for users to evaluate and compare the different model outcomes.

This step prepares for the visualisation in the next phase of the model. Here, a list of radii is inserted as the input of this process and based on the radii the reachability of nodes within this radii are determined. For each radii, a shape file is generated that, depending on the specified metric, shows areas that are reachable within a certain time from the closest entry point. Besides the entry points, other points of interest in the network, such as additional logistical hubs, can be specified by the user.

In detail, this process is defined as follows; for each entry point the latitude and longitude are determined and the 'great circle' distances between the selected entry point coordinates and each of the nodes present in the graph are calculated using the 
Haversine formula, as shown in Equation 4, which calculates the shortest distance between two points on the surface of a sphere, measured along the surface of the sphere (Gade 2010).

$$
\begin{aligned}
d_{a c} & =2 r \arcsin \sqrt[2]{\sin ^{2}\left(\frac{\phi_{c}-\phi_{a}}{2}\right)+\cos \left(\phi_{a}\right) \cos \left(\phi_{c}\right) \sin ^{2}\left(\frac{\lambda_{c}-\lambda_{a}}{2}\right)} \\
I_{a} & =\arg \min _{x}\left\{d_{a x}: x \in C\right\}
\end{aligned}
$$

where $d$ is the great circle distance between entry point $a$ and node $c, r$ is the radius of the sphere (the earth in this context), $\phi_{a}$ and $\phi_{c}$ are the geographical latitudes in radians of entry points $a$ and node $c$, and $\lambda_{a}$ and $\lambda_{c}$ are the longitudes in radians of entry point $a$ and node $c$, and $C$ is the set of all nodes in the graph (Gade 2010). $I_{a}$ is the node identifier that's being determined which is calculated by finding the node identifier with the lowest distance $d$.

The result of the above process is that for each entry point we know the distance between it and each other node in the graph. This allows us to determine for each node which entry point is closest, which is used to draw the shape files mentioned above.

In the last phase, all information from the previous phases is combined and a map of the user specified area is generated. The map shows entry points in blue, the ten most critical nodes and edges (with the highest betweenness centrality) are visualised as well (in black). Shape files are used to indicate the reachability of different areas. See Fig. $4 a$, $b$ in the next section for examples of generated maps.

\section{Case study: Papua New Guinea}

\subsection{Profile and background}

A 7.5 magnitude earthquake struck the Western Province of Papua New Guinea on 26 February 2018. The affected area was sparsely populated, with a dispersed population living in remote rural communities, and as such relying heavily on logistics networks for access. Figure 1 provides an overview of the most important logistics infrastructure, i.e., the airports, in the affected area. More than 500,000 people were affected by the disaster and rattled by a series of aftershocks (Government of Papua New Guinea 2018a). As water was reported to be scarce in affected areas due to damage to storage facilities and water sources, urgency was high to reach the estimated 247,000 people in need of immediate assistance (Government of Papua New Guinea 2018 b). Figure 2 provides some examples of maps used by humanitarian organisations in the post-disaster phase. On 1 March, an immediate State of Emergency was been declared (World Health Organization (WHO) 2018). On March 7, as one of the first maps released to guide teams to the disaster-affected areas, The United Nations Disaster Assessment and Coordination (UNDAC) organisation and the government of Papua New Guinea released a first map and infographic as shown in Fig. 2a. Only on March 21, a map that provides an overview of access conditions was released, see Fig. 2b. 


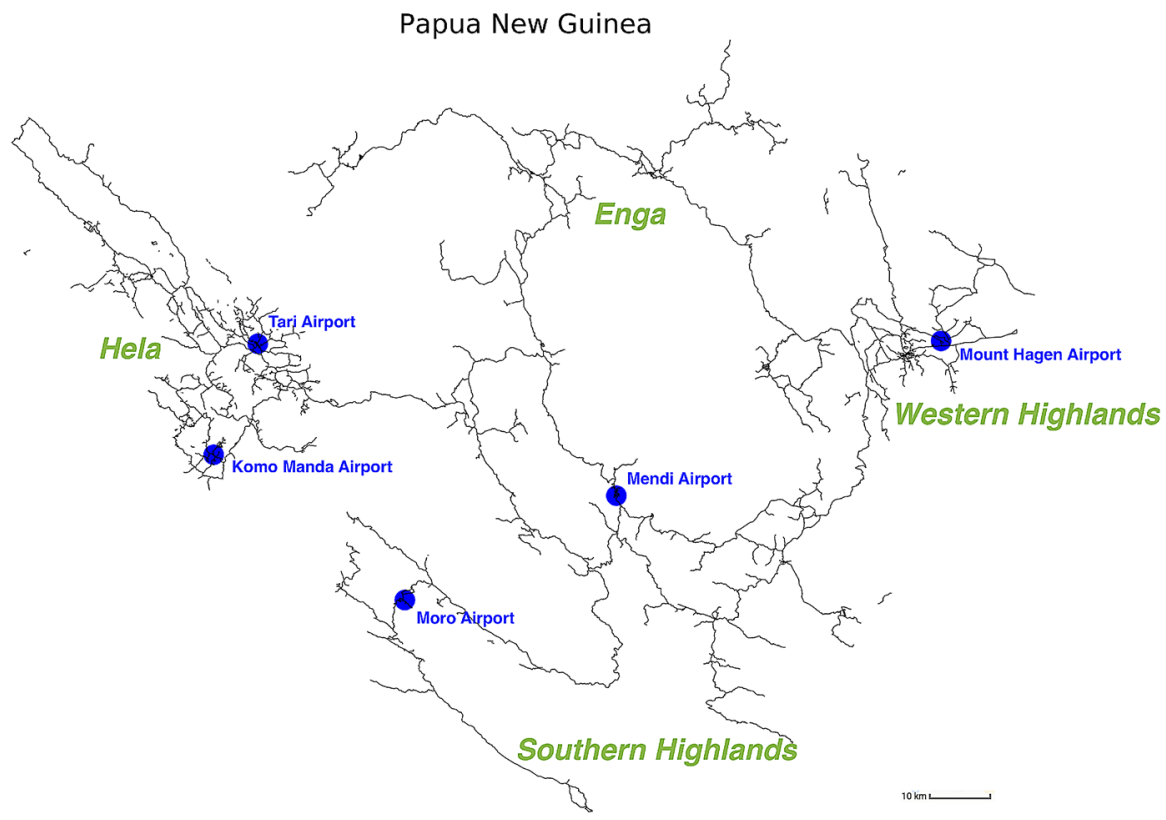

Fig. 1 Overview of main roads, airports (blue dots) and provinces (green description) in the disaster area in Papua New Guinea. Map created in Python based on OSM data (colour figure online)

We first model the road quality. Based on reports of the affected areas as indicated in Fig. 2b, we cover the provinces Hela, Southern Highlands, Western Highlands and Enga. The airports considered are Tari Airport, Moro Airport, Mendi Airport, Mount Hagen Airport and Komo Manda Airport (see Fig. 1 for geographical locations and place names. The average vehicle speed is estimated at $25 \mathrm{~km} / \mathrm{h}$ based on OpenStreetMap travel times.

\subsection{Model configuration}

Based on the access conditions, we modelled road transportation disruptions and operational airports. Figure 3 shows the drastic decline of road quality after the earthquake (Fig. 3b) as opposed to the un-disrupted conditions pre-disaster (Fig. 3a). After the disaster, Komo-Manda Airport was only accessible by helicopters and is therefore omitted from the model. To compensate for a lack of real traffic and disruptions times, we assumed that the roads that were reported 'open' can be used as in pre-disaster state and that disrupted roads have a road quality ranging from slightly smaller than 1 (almost no effect on travel speed) to a road quality of 0 for closed roads. The model travel speed is then determined by multiplying the road quality with the travel time, e.g., if the road quality is 0.5 and the travel time is $50 \mathrm{~km} / \mathrm{h}$ then the modelled travel time is $25 \mathrm{~km} / \mathrm{h}$.

Figure 4a shows that although the area around Komo and Tari (green area on the left of the figure) are well-reachable, even in pre-disaster context, the road network has 


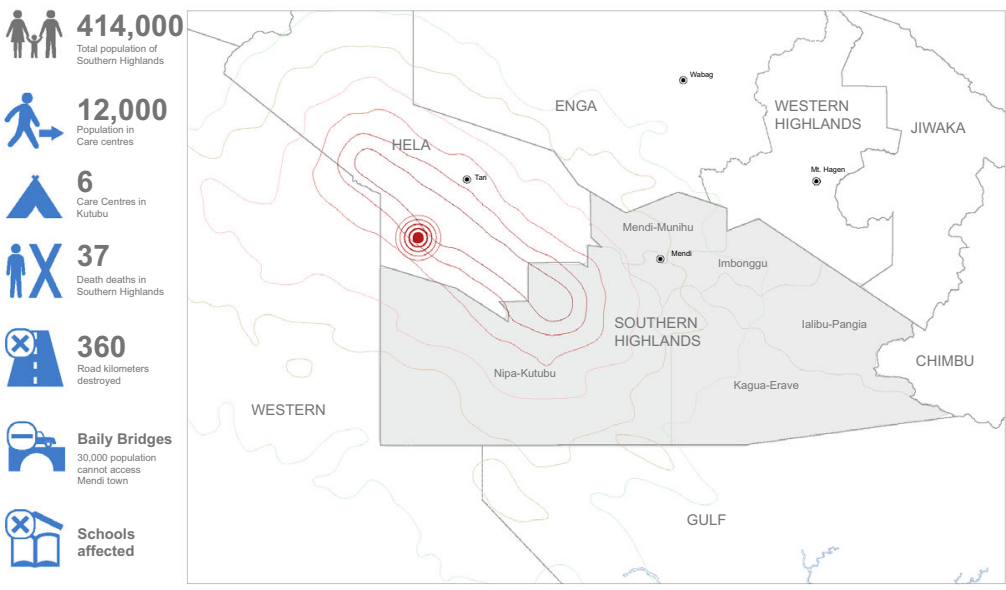

(a) Papua New Guinea - Situation Update March 7, 2018, (Government of Papua New Guinea and UNDAC Country team, 2018)
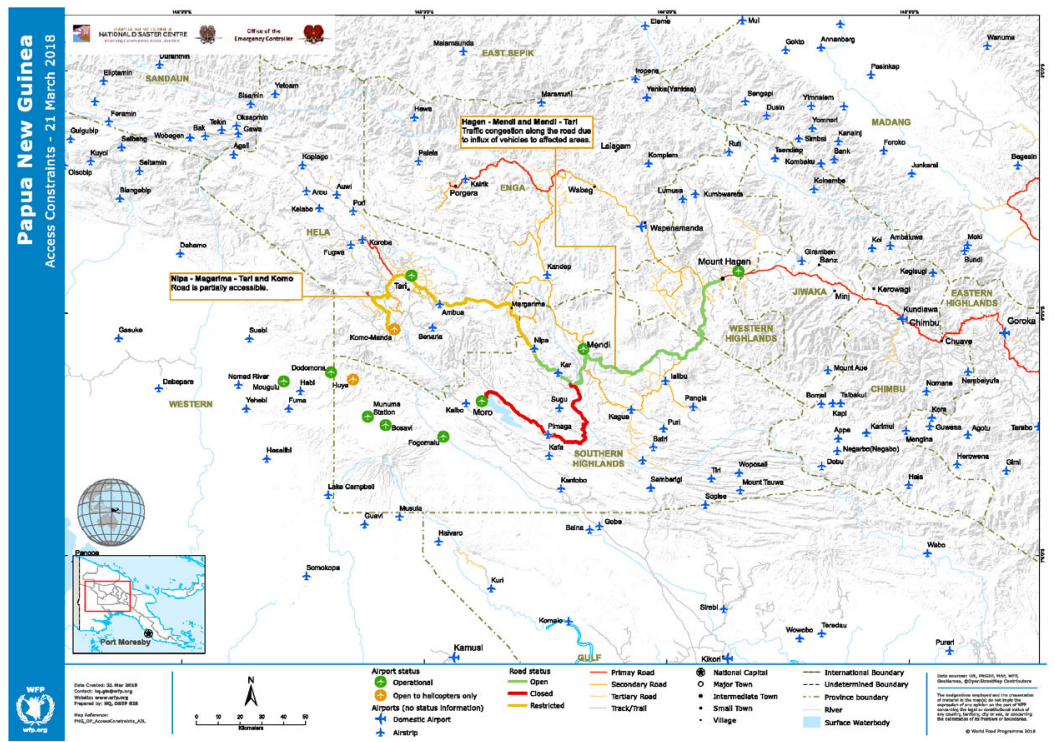

(b) Papua New Guinea Airport access, published March 21 (World Food Program, 2018).

Fig. 2 Examples of maps used by humanitarian organisations in the aftermath of the Papua New Guinea earthquake from February 26, 2018 


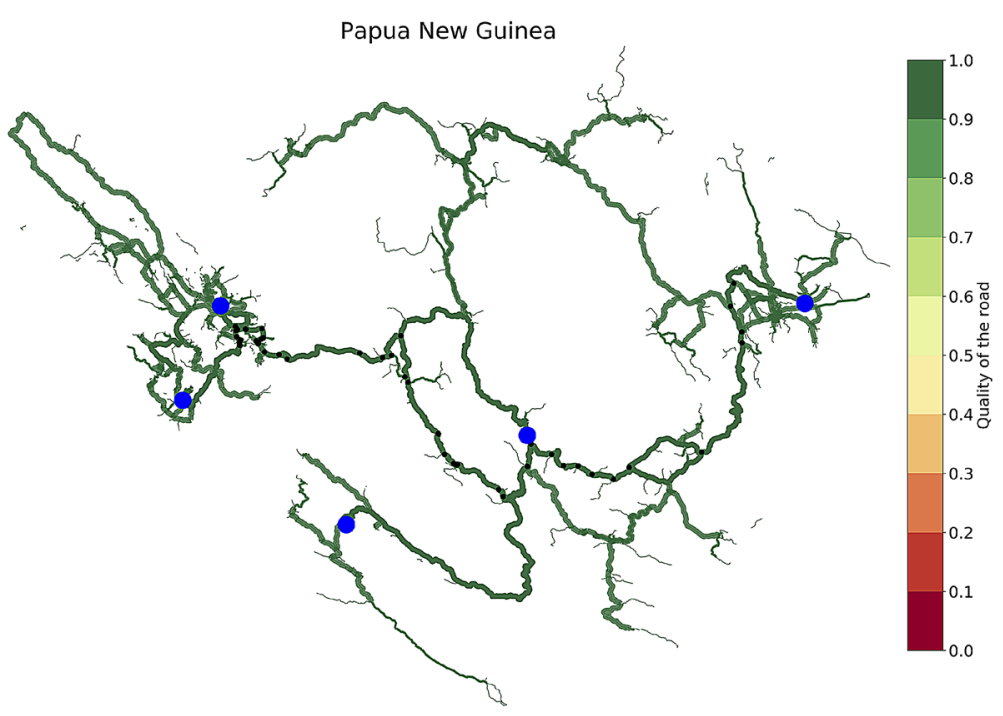

(a) Road Quality Pre-Disaster

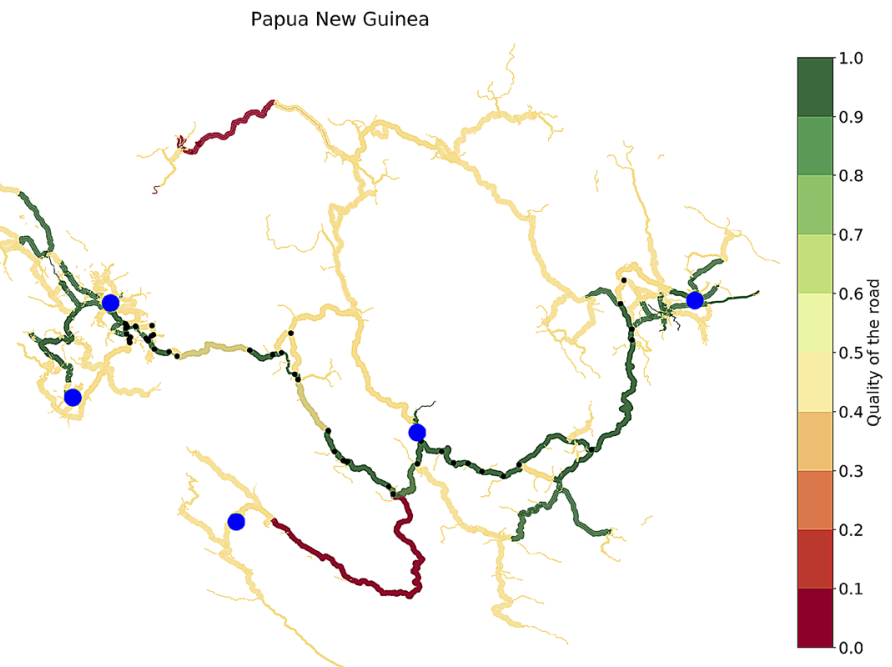

(b) Road Quality Post Disaster

Fig. 3 Model output: visualisations of road quality before (left) and after disaster (right). Figure 4a, b are based on this road quality data. Green: road quality $=1$; yellow: road quality $=0.5$; red: road quality $=$ 0. All model input data used for these visualizations comes from www.openstreetmap.org (colour figure online) 


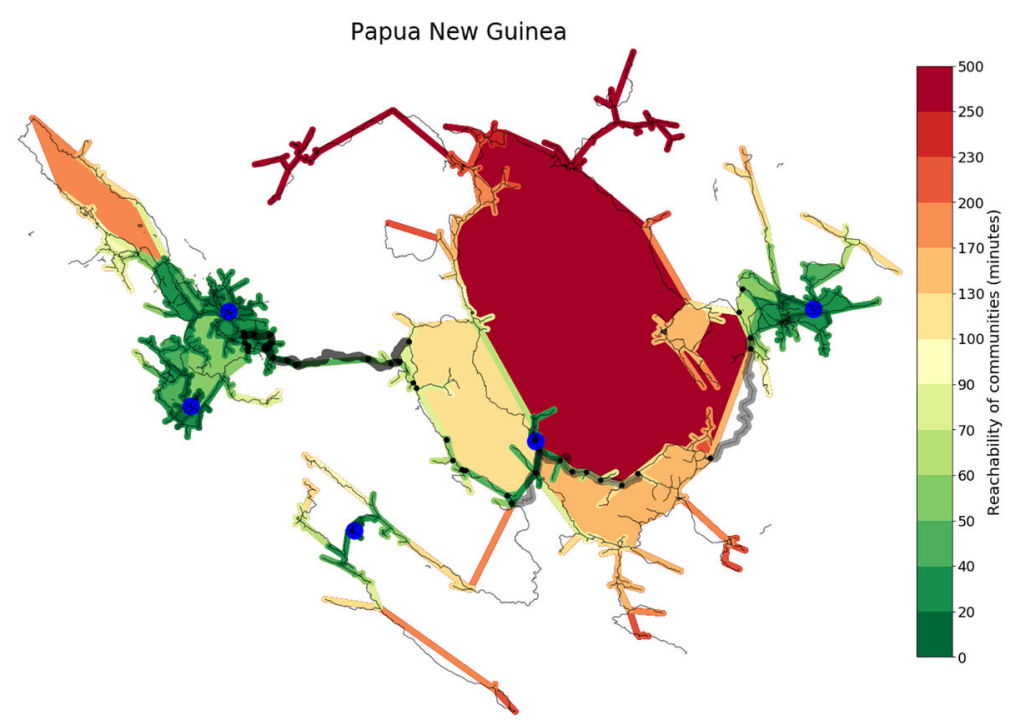

(a) Reachability Pre-Disaster Context

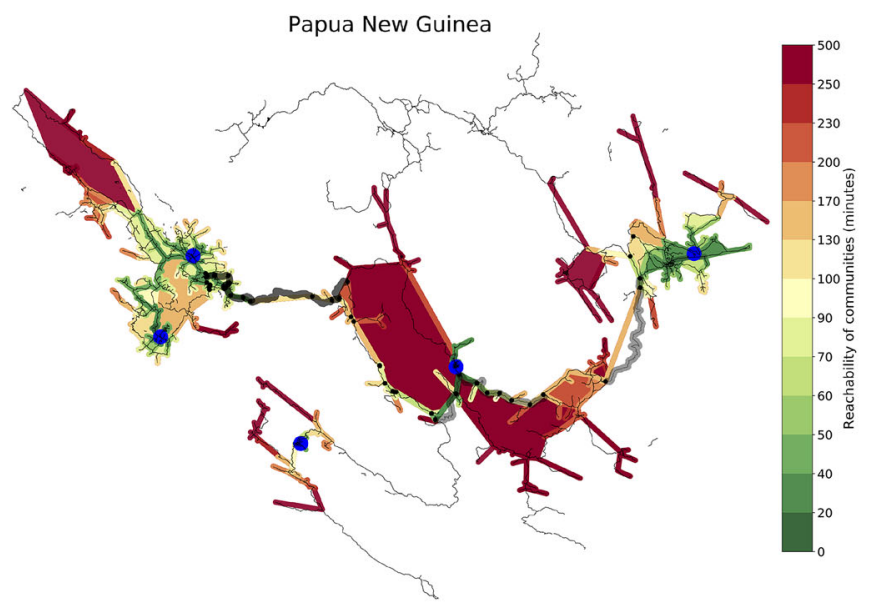

(b) Reachability in Post-Disaster Context

Fig. 4 Visualisation of reachability for Papua New Guinea. The blue dots are the airports, the black dots are the most important road junctions that connect the region with the entry points, the wider black edges are the most important road segments that connect the region with the entry points. The radii for which the reachability is measured are configured for: $[20,40,50,60,70,90,100,130,170,200,230,250,500]$ in minutes (colour figure online) 
several vulnerabilities. The connection from Komo and Tari to the East, with Mendi as next major hub, is a highly critical connection, indicated by the black dots. The figure also highlights that many areas in the Western Highlands are hard to reach, with a travel time that exceeds $8 \mathrm{~h}$ (corresponding to one day of travelling). Most vulnerable are the areas that are not highlighted in any colour, as these cannot be reached within one day, including the Southern Highlands (South of Mendi).

In contrast, Fig. 4b, shows the situation for the post-disaster context, based on information from the logistics cluster, cf. Fig. 2b. The destruction of an already vulnerable network road implies that vast areas in the provinces Hela, Enga and the Southern Highlands could not be reached, and that dependence on air transportation and helicopter lift was dramatically increased. We can also see that the most critical nodes and edges (in black) stay virtually the same, indicating that the relative betweenness centrality for both nodes and edges does not change, i.e., the most critical edges and nodes are the same before and after the disaster. We also notice a drastic reduction in travel time for the overall road network, going from less than 2 min on average per link to slightly more then $30 \mathrm{~min}$ on average per link.

A combination with assessment data allows to inform relief operations. While Komo (11.700 people affected) and Pai (12.000 people) could be reached via Tari Airport, other highly affected locations such as Kutubu Lake (5.300) could not be reached at all. ${ }^{5}$

At the same time, these findings also highlight the criticality of some hubs and connections such as Tari. Indeed, further into the disaster, these connections became subject to roadblocks, where violent groups demanded compensation for safe passage. ${ }^{6}$ As such, rapidly available information about the location and criticality of roads or airports should inform the allocation of resources for safety and security measures.

\subsection{Feasibility and validity}

The case study on Papua New Guinea of February allows us to evaluate the technical and practical feasibility for a relatively large area with limited availability of road data. The configuration runtime is around $15 \mathrm{~min}$ on a personal laptop. We integrated edge-id information from OpenStreetMap, but since much of the information about street names were missing, it was time-consuming to adjust the road quality for specific road segments. Moreover, the reachability maps are combined with humanitarian parameters derived from maps showing the affected populations. We explicitly focus here on reachability via road for transportation of larger goods and convoys. Last mile distribution, e.g., via motorbike or on foot is not included here.

The main advantage of the model is thus that it can quickly, i.e., within hours after an event, be used to generate an initial map using open data from OpenStreetMap. In contrast, it now takes days, as illustrated for the Papua New Guinea case, to provide reachability maps in the aftermath of a disaster. The main challenge is to acquire accurate data with respect to road quality that can be used to generate better maps. In

\footnotetext{
5 Data on affected population from European Union (2018).

6 https://reliefweb.int/sites/reliefweb.int/files/resources/png_op_logsoverview_a31_20180625.pdf.
} 
particular in the post-disaster phase when there is a lot of uncertainty about the current situation.

To evaluate the feasibility of the model further, semi-structured interviews with two experts were conducted. Questions focused on feasibility and usefulness of the model, and potential improvements. Both experts had a background in logistics, as a member of the response team of the Dutch Royal Navy, and as response team from the United Nations. An interview protocol is provided in "Appendix".

Both interviewees confirm that the model offers significant gains in information processing time, and allows to rapidly establish an overview of the situation. As such, potential application areas include prioritisation of core regions for emergency response, location of shelters and (temporary) medical facilities, as well as monitoring and safety of critical elements of the road infrastructure network.

The main limitations were seen as the lack of integration of traffic data or predictions (such as congestion). In addition, the interviewees agreed that a more exploratory use of the model (in terms of investigating several disruption scenarios) could be helpful.

\section{Discussion and conclusions}

This paper proposes an information system that uses a combination of OpenStreetMap and open humanitarian data to provide a near real-time overview of the reachability and access to affected communities in the period directly after a sudden onset disaster. The information system supports logistics planning in determining access to affected communities. A case study on the 2018 earthquake in Papua New Guinea demonstrates the feasibility and validity of our approach, which is confirmed by independent experts.

We argue that this approach is making a headway in connecting new data analytics that dynamically adapt to a changing situation and traditional OR methods. First, our reachability approach provides data and analysis on the status of the network that can feed into a variety of operations research problems, such as vehicle routing (Al Theeb and Murray 2017; Campbell et al. 2008) or (last mile) distribution (Balcik et al. 2008), allowing them to dynamically adapt to the situation. Second, the analysis of criticality can feed into scheduling and resource allocation models that optimise the use of resources for Schryen et al. (2015), e.g., for the removal of debris (Berktaş et al. 2016). Lastly, this approach also supports longer-term facility location planning (Balcik and Beamon 2008; Baharmand et al. 2019), by analysing the reachability of a facility (or community from the chosen location).

For future work, we want to explore if it is possible to extract relevant contextual information automatically, for example from sensor data or satellite images, and to explore the possibility to integrate traffic data or predictions thereof in the information system. Both of these should enhance the situational awareness of aid workers. Another line of research is to explore how scalable to the approach is, i.e., how much information can be processed in a reasonable amount of time and how large can these kind of maps be? The possibility to offload the computations to, for example, a cloud infrastructure should be explored here. 
Open Access This article is licensed under a Creative Commons Attribution 4.0 International License, which permits use, sharing, adaptation, distribution and reproduction in any medium or format, as long as you give appropriate credit to the original author(s) and the source, provide a link to the Creative Commons licence, and indicate if changes were made. The images or other third party material in this article are included in the article's Creative Commons licence, unless indicated otherwise in a credit line to the material. If material is not included in the article's Creative Commons licence and your intended use is not permitted by statutory regulation or exceeds the permitted use, you will need to obtain permission directly from the copyright holder. To view a copy of this licence, visit http://creativecommons.org/licenses/by/4.0/.

\section{Appendix: Interview protocol for model evaluation}

For the evaluation of the model in addition to the case-studies, field experts are consulted and interviewed to explore whether the model can potentially support decision-making and what important limitations of the model are. Two experts have been approached to conduct a semi-structured interview with. The interview protocol with questions is described below.

\section{Questions}

- Have you been involved in humanitarian aid operations during rapid onset disasters?

- What are, according to you, the most important decisions that have to be made during these type of humanitarian aid operations?

- During humanitarian aid operations, what kind of problems did you experience that are directly related to information provisioning?

- Do you think that the proposed information system can have added value during humanitarian aid operations?

- If you agree that the proposed information system can have added value during humanitarian aid operations, can you think of operational examples where the information system would be particularly useful?

- Are there any major limitations you see to our approach?

- Do you have anything else to add?

\section{References}

Al Theeb N, Murray C (2017) Vehicle routing and resource distribution in postdisaster humanitarian relief operations. Int Trans Oper Res 24:1253-1284

Albert R, Jeong H, Barabási AL (2000) Error and attack tolerance of complex networks. Nature 406:378-382. https://doi.org/10.1038/35019019

Altay N, Labonte M (2014) Challenges in humanitarian information management and exchange: evidence from Haiti. Disasters 38:S50-S72

Anaya-Arenas AM, Renaud J, Ruiz A (2014) Relief distribution networks: a systematic review. Ann Oper Res 223:53-79

Aydin NY, Duzgun HS, Wenzel F, Heinimann HR (2018) Integration of stress testing with graph theory to assess the resilience of urban road networks under seismic hazards. Nat Hazards 91:37-68

Baharmand H, Comes T, Lauras M (2017) Managing in-country transportation risks in humanitarian supply chains by logistics service providers: insights from the 2015 nepal earthquake. Int J Disaster Risk Reduct 24:549-559

Baharmand H, Comes T, Lauras M (2019) Bi-objective multi-layer location-allocation model for the immediate aftermath of sudden-onset disasters. Transp Res Part E Logist Transp Rev 127:86-110

Balcik B, Beamon BM (2008) Facility location in humanitarian relief. Int J Logist 11:101-121 
Balcik B, Beamon BM, Smilowitz K (2008) Last mile distribution in humanitarian relief. J Intell Transp Syst 12:51-63. https://doi.org/10.1080/15472450802023329

Balcik B, Beamon BM, Krejci CC, Muramatsu KM, Ramirez M (2010) Coordination in humanitarian relief chains: practices, challenges and opportunities. Int J Prod Econ 126:22-34. https://doi.org/10.1016/j. ijpe.2009.09.008

Bell MG, Iida Y (1997) Transportation network analysis. Wiley, Hoboken

Ben-Naim E, Frauenfelder H, Toroczkai Z (2004) Complex networks, vol 650. Springer, Berlin

Berktaş N, Kara BY, Karaşan OE (2016) Solution methodologies for debris removal in disaster response. EURO J Comput Optim 4:403-445

Bharosa N, Lee J, Janssen M (2010) Challenges and obstacles in sharing and coordinating information during multi-agency disaster response: propositions from field exercises. Inf Syst Front 12:49-65

Birkmann J (2007) Risk and vulnerability indicators at different scales: applicability, usefulness and policy implications. Environ Hazards 7:20-31

Boccaletti S, Latora V, Moreno Y, Chavez M, Hwang DU (2006) Complex networks: structure and dynamics. Phys Rep 424:175-308

Brandes U (2001) A faster algorithm for betweenness centrality. J Math Sociol 25:163-177

Brandes U (2008) On variants of shortest-path betweenness centrality and their generic computation. Soc Netw 30:136-145. https://doi.org/10.1016/j.socnet.2007.11.001

Campbell AM, Vandenbussche D, Hermann W (2008) Routing for relief efforts. Transp Sci 42:127-145

Cats O, Koppenol GJ, Warnier M (2017) Robustness assessment of link capacity reduction for complex networks: application for public transport systems. Reliab Eng Syst Saf 167:544-553

Chandes J, Paché G (2010) Investigating humanitarian logistics issues: from operations management to strategic action. J Manuf Technol Manag 21:320-340. https://doi.org/10.1108/17410381011024313

Chowdhury S, Emelogu A, Marufuzzaman M, Nurre SG, Bian L (2017) Drones for disaster response and relief operations: a continuous approximation model. Int J Prod Econ 188:167-184

Comes T, Van de Walle B (2016) Information systems for humanitarian logistics: concepts and design principles. In: Kovacs G, Spens K, Haavisto I (eds) Supply chain management for humanitarians: tools for practice. Kogan Page, London, pp 257-284

Comes T, Hiete M, Wijngaards N, Schultmann F (2011) Decision maps: a framework for multi-criteria decision support under severe uncertainty. Decis Support Syst 52:108-118

Comes T, Vybornova O, Van de Walle B (2015) Bringing structure to the disaster data typhoon: an analysis of decision-makers' information needs in the response to Haiyan. In: Proceedings of the AAAI spring symposium series (SSS-15) on structured data for humanitarian technologies: perfect fit or overkill, pp. $23-25$

Comes T, Meesters K, Torjesen S (2017) Making sense of crises: the implications of information asymmetries for resilience and social justice in disaster-ridden communities. Sustain Resilient Infrastruct. https:// doi.org/10.1080/23789689.2017.1405653

Comes T, Bergtora Sandvik K, Van de Walle B (2018) Cold chains, interrupted: the use of technology and information for decisions that keep humanitarian vaccines cool. J Humanit Logist Supply Chain Manag 8:49-69

Dijkstra EW (1959) A note on two problems in connexion with graphs. Numer Math 1:269-271

Easley D, Kleinberg J (2010) Networks, crowds, and markets: reasoning about a highly connected world. Cambridge University Press, Cambridge

Endsley MR (1988) Design and evaluation for situation awareness enhancement. Proc Hum Factors Soc Annu Meet 32:97-101. https://doi.org/10.1177/154193128803200221

European Union (2018) Papua New Guinea I Earthquakes Aftermath

Gade K (2010) A non-singular horizontal position representation. J Navig R Inst Navig 63:395-417. https:// doi.org/10.1017/S0373463309990415

Government of Papua New Guinea, UN OCHA, UNDAC Country Team (2018a) Papua New Guinea: highlands earthquake situation report no. 1 (as of 10 March 2018). https://reliefweb.int/report/papuanew-guinea/papua-new-guinea-highlands-earthquake-situation-report-no-1-10-march-2018

Government of Papua New Guinea, UN OCHA, UNDAC Country Team (2018b) Papua New Guinea: highlands earthquake situation report no. 3 (as of 17 March 2018). https://reliefweb.int/report/papuanew-guinea/papua-new-guinea-highlands-earthquake-situation-report-no-1-10-march-2018

Government of Papua New Guinea, UNDAC Country Team (2018c) Papua New Guinea: 7.5 earthquake-southern highlands province snapshot (7 March 2018) 
Guimerá R, Amaral LAN (2004) Modeling the world-wide airport network. Eur Phys J B Condens Matter 38:381-385. https://doi.org/10.1140/epjb/e2004-00131-0

Harrald JR (2006) Agility and discipline: critical success factors for disaster response. Ann Am Acad Polit Soc Sci 604:256-272. https://doi.org/10.1177/0002716205285404

Harvard Humanitarian Initiative (HHI) (2010) Disaster relief 2.0: the future of information sharing in humanitarian emergencies. HHI; United Nations Foundation; OCHA; The Vodafone Foundation

Hernandez JM, Van Mieghem P (2011) Classification of graph metrics, pp 1-20. https://www.nas.ewi. tudelft.nl/people/Piet/papers/TUDreport20111111_MetricList.pdf. Accessed 28 Feb 2020

Hevner A, March S, Park J, Ram S (2004) Design science in the information systems discipline: an introduction to the special issue on design science research. MIS Q 28:75-105

Holguín-Veras J, Jaller M, Van Wassenhove LN, Pérez N, Wachtendorf T (2012) On the unique features of post-disaster humanitarian logistics. J Oper Manag 30:494-506

Huang Q, Xiao Y (2015) Geographic situational awareness: mining tweets for disaster preparedness, emergency response, impact, and recovery. ISPRS Int J Geo Inf 4:1549-1568. https://doi.org/10.3390/ ijgi4031549

Huyck C, Verrucci E, Bevington J (2014) Remote sensing for disaster response. In: Shroder JF, Wyss M (eds) Earthquake hazard, risk and disasters. Elsevier, Amsterdam. https://doi.org/10.1016/B978-0-12394848-9.00001-8

Jenelius E, Mattsson LG (2012) Road network vulnerability analysis of area-covering disruptions: a gridbased approach with case study. Transp Res Part A Policy Pract 46:746-760

Kazmin A (2015) Nepal earthquake: rescuers struggle to reach remote villages. https://www.ft.com/content/ 838455e4-ec0e-11e4-b428-00144feab7de. Accessed 28 Feb 2020

Kogan M, Anderson J, Palen L, Anderson KM, Soden R (2016) Finding the way to OSM mapping practices: bounding large crisis datasets for qualitative investigation. In: Proceedings of the $2016 \mathrm{CHI}$ conference on human factors in computing systems, ACM, New York, NY, USA, pp 2783-2795. https://doi.org/ $10.1145 / 2858036.2858371$

Laguna-Salvadó L, Lauras M, Okongwu U, Comes T (2018) A multicriteria master planning DSS for a sustainable humanitarian supply chain. Ann Oper Res 283:1303-1343

Lu X, Bengtsson L, Holme P (2012) Predictability of population displacement after the 2010 Haiti earthquake. Proc Natl Acad Sci 109:11576-11581

Madey GR, Barabási AL, Chawla NV, Gonzalez M, Hachen D, Lantz B, Pawling A, Schoenharl T, Szabó G, Wang P, Yan P (2007) Enhanced situational awareness: application of DDDAS concepts to emergency and disaster management. In: Shi Y, van Albada GD, Dongarra J, Sloot PMA (eds) Computational science-ICCS 2007. Springer, Berlin, pp 1090-1097. https://doi.org/10.1007/978-3-540-72584-8_ 143

Meier P (2015) Digital humanitarians: how big data is changing the face of humanitarian response. Routledge, Abingdon

Middleton SE, Middleton L, Modafferi S (2014) Real-time crisis mapping of natural disasters using social media. IEEE Intell Syst 29:9-17

Mitsakis E, Salanova JM, Stamos I, Chaniotakis E (2016) Network criticality and network complexity indicators for the assessment of critical infrastructures during disasters. In: Kotsireas IS, Nagurney A, Pardalos PM (eds) Springer proceedings in mathematics \& statistics, vol 185. Springer, Cham, pp 191-205. https://doi.org/10.1007/978-3-319-43709-5

Özdamar L, Ertem MA (2015) Models, solutions and enabling technologies in humanitarian logistics. Eur J Oper Res 244:55-65

Palen L, Anderson KM (2016) Crisis informatics—new data for extraordinary times. Science 353:224-225

Papadopoulos T, Gunasekaran A, Dubey R, Altay N, Childe SJ, Fosso-Wamba S (2017) The role of big data in explaining disaster resilience in supply chains for sustainability. J Clean Prod 142:1108-1118. https:// doi.org/10.1016/j.jclepro.2016.03.059 (special volume on improving natural resource management and human health to ensure sustainable societal development based upon insights gained from working within 'Big Data Environments')

Prasad S, Zakaria R, Altay N (2018) Big data in humanitarian supply chain networks: a resource dependence perspective. Ann Oper Res 270:383-413

Preston BL, Yuen EJ, Westaway RM (2011) Putting vulnerability to climate change on the map: a review of approaches, benefits, and risks. Sustain Sci 6:177-202. https://doi.org/10.1007/s11625-011-01291 
Salvadó LL, Lauras M, Comes T, Van de Walle B (2015) Towards more relevant research on humanitarian disaster management coordination. In: ISCRAM

Schintler LA, Kulkarni R, Gorman S, Stough R (2007) Using raster-based GIS and graph theory to analyze complex networks. Netw Spat Econ 7:301-313. https://doi.org/10.1007/s11067-007-9029-4

Schryen G, Rauchecker G, Comes T (2015) Resource planning in disaster response. Bus Inf Syst Eng 57:243-259

Strogatz SH (2001) Exploring complex networks. Nature 410:268

Tatham P, Spens K, Kovács G (2017a) The humanitarian common logistic operating picture: a solution to the inter-agency coordination challenge. Disasters 41:77-100

Tatham P, Stadler F, Murray A, Shaban RZ (2017b) Flying maggots: a smart logistic solution to an enduring medical challenge. J Humanit Logist Supply Chain Manag 7:172-193

Tomaszewski B (2011) Situation awareness and virtual globes: applications for disaster management. Comput Geosci 37:86-92. https://doi.org/10.1016/J.CAGEO.2010.03.009

Turoff M, Chumer M, de Walle BV, Yao X (2004) The design of a dynamic emergency response management information system (dermis). J Inf Technol Theory Appl (JITTA) 5:3

United Nations Papua New Guinea (2018) Papua New Guinea: earthquake reference map with affected villages

Van de Walle B, Comes T (2015) On the nature of information management in complex and natural disasters. Procedia Eng 107:403-411

Van de Walle B, Van Den Eede G, Muhren W (2008) Humanitarian information management and systems. In: International workshop on mobile information technology for emergency response, Springer, pp 12-21

Van de Walle B, Brugghemans B, Comes T (2016) Improving situation awareness in crisis response teams: an experimental analysis of enriched information and centralized coordination. Int $\mathrm{J}$ Hum Comput Stud 95:66-79

Van Wassenhove LN (2006) Humanitarian aid logistics: supply chain management in high gear. J Oper Res Soc 57:475-489. https://doi.org/10.1057/palgrave.jors.2602125

van Wynsberghe A, Comes T (2019) Drones in humanitarian contexts, robot ethics, and the human-robot interaction. Ethics Inf Technol. https://doi.org/10.1007/s10676-019-09514-1

World Food Program (2018) Papua New Guinea Airport access

World Health Organization (WHO) (2018) Papua New Guinea earthquake: situation report, 20 March 2018. https://reliefweb.int/report/papua-new-guinea/papua-new-guinea-earthquake-situation-report20-march-2018

Publisher's Note Springer Nature remains neutral with regard to jurisdictional claims in published maps and institutional affiliations. 